\title{
Sexual selection and the function of a melanin-based plumage ornament in polygamous penduline tits Remiz pendulinus
}

\author{
Sjouke A. Kingma • István Szentirmai • Tamás Székely • \\ Veronika Bókony • Maarten Bleeker • András Liker • \\ Jan Komdeur
}

Received: 13 February 2007 / Revised: 31 January 2008 / Accepted: 31 January 2008 / Published online: 28 February 2008

(C) The Author(s) 2008

\begin{abstract}
Melanin-based ornaments are often involved in signaling aggression and dominance, and their role in sexual selection is increasingly recognized. We investigated the functions of a melanin-based plumage ornament (facial 'mask') in male Eurasian penduline tits Remiz pendulinus in the contexts of male-male aggression, mating success,
\end{abstract}

Communicated by K. McGraw

S. A. Kingma $\cdot$ M. Bleeker $\cdot$ J. Komdeur $(\bowtie)$

Animal Ecology Group,

Centre for Ecological and Evolutionary Studies,

University of Groningen,

P.O. Box 14, 9750 AA Haren, The Netherlands

e-mail: j.komdeur@rug.nl

S. A. Kingma

Max Planck Institute for Ornithology,

Behavioural Ecology of Sexual Signals Group,

Vogelwarte Radolfzell, Schlossallee 2,

78315 Radolfzell, Germany

\section{Szentirmai}

Department of Ethology, Eötvös Loránd University,

Pázmány P. sétány $1 / \mathrm{C}$,

1117 Budapest, Hungary

T. Székely

Department of Biology and Biochemistry, University of Bath,

Bath BA2 7AY, UK

\section{Bókony}

Department of Ecology, Szent István University,

Rottenbiller u. 50

1077 Budapest, Hungary

A. Liker

Department of Limnology, University of Pannonia,

Pf. 158 ,

8201 Veszprém, Hungary and parental care. The penduline tit is a passerine bird with a unique mating system in which both sexes may mate with several mates in a breeding season, and one (or both) parent deserts the clutch. Our study revealed that mask size of males is more likely an honest signal used by females in their mate choice decisions than a trait involved in malemale competition. First, mask size increased with both age and body condition, indicating that the mask may signal male quality. Second, males with larger masks paired more quickly and had more mates over the breeding season than males with smaller masks. Third, we found no evidence that male mask size signals male-male aggression or dominance during competitive encounters. The increased mating success of large-masked males, however, did not translate into higher reproductive success, as nestling survival decreased with mask size. Therefore, we conclude that there is either no directional selection on male mask size or males with larger masks receive indirect, long-term benefits.

Keywords Female choice - Brood desertion .

Ornamentation $\cdot$ Feather coloration

\section{Introduction}

Melanin pigments that produce mainly black or dark colors are common sources of skin, hair, and plumage colors of animals (Jawor and Breitwisch 2003; McGraw 2006). Because these colors are often perceived as dull or cryptic, much research has focused on their non-sexual functions, e.g., strengthening feathers to resist abrasion (reviewed by Savalli 1995), or antimicrobial effects in the skin (Mackintosh 2001). Conspicuous melanin ornaments, such 
as black patches, were traditionally viewed as arbitrary badges of status in social competition among conspecifics, as melanin ornaments signal dominance rank in birds (reviewed by Senar 1999) and lizards (Zucker 1994; Quinn and Hews 2003). Relatively few studies have investigated the role of melanin ornaments in sexual signaling and particularly in female choice, and even fewer studies provide evidence that females prefer more melanized males (reviewed by Hill 2006). Furthermore, experimental studies often failed to demonstrate the dependence of melanin ornaments on nutritional condition or health status (Hill and Brawner 1998; Roulin et al. 1998; Gonzalez et al. 1999; McGraw and Hill 2000; McGraw et al. 2002; Senar et al. 2003; Siefferman and Hill 2005; Bize et al. 2006; for review, see Griffith et al. 2006). The latter results were consistent with phylogenetic comparative analyses that suggested sexual selection is unlikely to have a strong effect on melanin-based plumage dimorphism in birds (Gray 1996; Badyaev and Hill 2000).

However, melanin-based coloration has received more interest recently because researchers realized melanin ornaments may be costly to produce, and they may honestly reflect individual quality (McGraw 2003; for reviews, see Jawor and Breitwisch 2003; Griffith et al. 2006). Accordingly, recent studies demonstrated that melanization can relate to mating success (Roulin 1999; Parker et al. 2003; Tarof et al. 2005), to resistance to ectoparasites (Roulin et al. 2000, 2001a), or to parental effort (Roulin et al. 2001b; Siefferman and Hill 2003). Furthermore, recent phylogenetic studies showed that plumage melanization is related to sexual displays in shorebirds and bustards, as predicted by sexual selection theory (Bókony et al. 2003; Dale et al. 2006), and to reproductive investment in cardueline finches (Bókony and Liker 2005).

The role of melanin ornaments in sexual selection remains a controversial topic for at least two reasons. First, less melanized males may be preferred by females in some species, and these males therefore have higher reproductive success (Lemon et al. 1992; Griffith et al. 1999), perhaps because males with smaller melanin ornaments provide more parental care (Studd and Robertson 1985a, b; Griffith et al. 1999; but see Voltura et al. 2002), or are less dominant or aggressive (Jawor and Breitwisch 2003). Thus, melaninbased coloration appears to be involved in both intra- and intersexual signaling. Second, melanin-based plumage traits may be associated with alternative mating strategies, and thus selection for behavioral strategies or plumage trait may reinforce each other producing genetic polymorphism in both sets of traits (Lank et al. 1995, Roulin 2004).

In this paper, we investigate the role of a melanin-based ornament in male-male competition, male mating success, and parental care in a small passerine bird, the Eurasian penduline tit Remiz pendulinus (penduline tit henceforward). The penduline tit is an excellent species to investigate ornament evolution because it has a uniquely diverse reproductive system, with multiple breeding and females being able to mate and/or desert their mates. Males build up to nine nests consecutively during a single breeding season to attract females (Szentirmai et al. 2005). Competition for females is intense, as at about $40 \%$ of nests, the males are not successful attracting a female (Hoi et al. 1994; Szentirmai et al. 2005). Before the start of incubation, the male (or the female) deserts the clutch, and full care is provided by a single parent (Franz and Theiss 1983; Persson and Öhrström 1989; Franz 1991; Szentirmai et al. 2005). About one third of clutches, however, is naturally deserted by both parents, and Szentirmai et al. (2007) showed that biparental clutch desertion is an outcome of the intense sexual conflict between males and females. Deserting parents often remate and renest, and thus, both males and females are sequentially polygamous within a single breeding season. Traits involved in mate choice and parental care are largely unexplored in this unusual breeding system (but see Bleeker et al. 2005; Szentirmai et al. 2005; Pogány and Székely 2007). In this study, we focus on masks of males and test whether it is involved in male-male interactions, mating success, and parental care. Both males and females have conspicuous black masks that are most likely melanin-based, as no other pigment is known to produce pitch-black feathers in birds (Jawor and Breitwisch 2003; McGraw 2006).

The objective of our study was to test functional hypotheses of ornament evolution in the field using penduline tits as model organism. First, we test whether mask size reflects the males' body condition and age. Second, we test whether male masks signal intrasexual aggression and dominance. Third, we investigate whether male mask size relates to clutch desertion and care provisioning by males and females. Finally, we explore whether mating success and reproductive success of males are related to the size of their masks.

\section{Materials and methods}

Study site and morphometric measurements

We investigated the penduline tits at Fehértó, southern Hungary $\left(46^{\circ} 19^{\prime} \mathrm{N}, 20^{\circ} 5^{\prime} \mathrm{E}\right)$ during the entire breeding seasons of 2003 and 2004 (between April and August). Fehértó is an extensive fishpond system (1,321 ha), where penduline tits nest mainly on trees (poplar Populus spp. and willow Salix spp.) on the dykes among fishpond units (Szentirmai et al. 2005). We searched for nests everyday during the field season. Nest initiation date was determined 
for all nests. If a nest was found in an advanced building stage (see figures in Cramp et al. 1993), we estimated the nest initiation date using a predictor equation derived from nests that were found at initiation (Szentirmai et al. 2005). Nests were visited every other day for $15 \mathrm{~min}$ to monitor the presence and identity of the male at the nest and to establish whether he successfully paired. A male was defined as mated when he was copulating with a female and/or building the nest together with a female. Mated females spend most time on or around the nest, and nearly all nests we found were before the male mated ( 157 out of 163 nests of mated males). Males $(N=90)$ were caught at their first nest during nest building using a mist net, a dummy penduline tit, and song playback. Females $(N=28)$ were caught either together with their mate or during incubation in the nest using a net especially designed to catch incubating penduline tits (Barbácsy Z., personal communication). Each individual was ringed for identification using three-color rings and a numbered metal ring of the Hungarian Ornithological Institute, and weighed using a Pesola spring balance $( \pm 0.1 \mathrm{~g})$. Tarsus length was measured three times using a digital sliding calliper $( \pm 0.1 \mathrm{~mm})$, and the median values were recorded. Digital photographs were taken from each penduline tit at both sides of their head (three photos from each side), by keeping them in a standard position, horizontally in front of a graph paper (see Fig. 1). All photos were taken in the shade using a Fuji FinePix A203 digital camera (2 megapixel) without zoom and flashlight and at about $15 \mathrm{~cm}$ from the bird to create standard conditions. Eight individuals were caught and photographed twice for estimating repeatability (see below). In total, 60 and 62 males were present in 2003 and 2004, respectively. These males built on average 2.9 nests (range, $1-9)$ and 2.5 nests (range, 1-7), resulting in a total of 172 and 152 nests over the entire breeding seasons of 2003 and 2004, respectively. Although all males were color-banded, sample sizes may vary between analyses due to missing data on behavior or reproductive variables.

\section{Mask measurements}

Masks were measured on the digital photos by Corel PhotoPaint 9 (2001) using background grids for calibration (see Fig. 1), and mask size was calculated as the average area of the left and the right masks $\left( \pm 0.01 \mathrm{~cm}^{2}\right)$. Molting birds were excluded from the analyses because their masks could not be measured reliably ( $N=4$ males and 7 females).

Mask measurements were conducted blindly to the identity of birds by two observers (SAK, VB). Twenty birds were measured by both observers, and measures were highly repeatable between the observers $\left(R=0.9, F_{19,20}=\right.$ 18.3, $P<0.001$; for methods, see Lessells and Boag 1987). In addition, the mask measurements from different photographs of the same male were highly repeatable both between photographs that were taken on the same day $(R=$ $\left.0.9, F_{19,20}=37.5, P<0.001\right)$ and between photographs that were taken on different days (capture intervals varied between 9 and 36 days; $R=0.7, F_{7,8}=0.7, P=0.003$ ). Similarly, there was no difference in mask sizes between the first and the second captures of the same male (pairedsample $t$ test: $t_{7}=1.8, P=0.11$ ). Therefore, mask size appears to remain unchanged during the breeding season so that one measurement is representative for the entire season until molting starts. In addition, the high repeatabilities both within and between captures of a given individual indicate that our measurement error was small compared to the variation between different individuals.

\section{Body condition}

We used three indicators of physical condition: body mass, hematocrit value, and presence/absence of buffy coat in
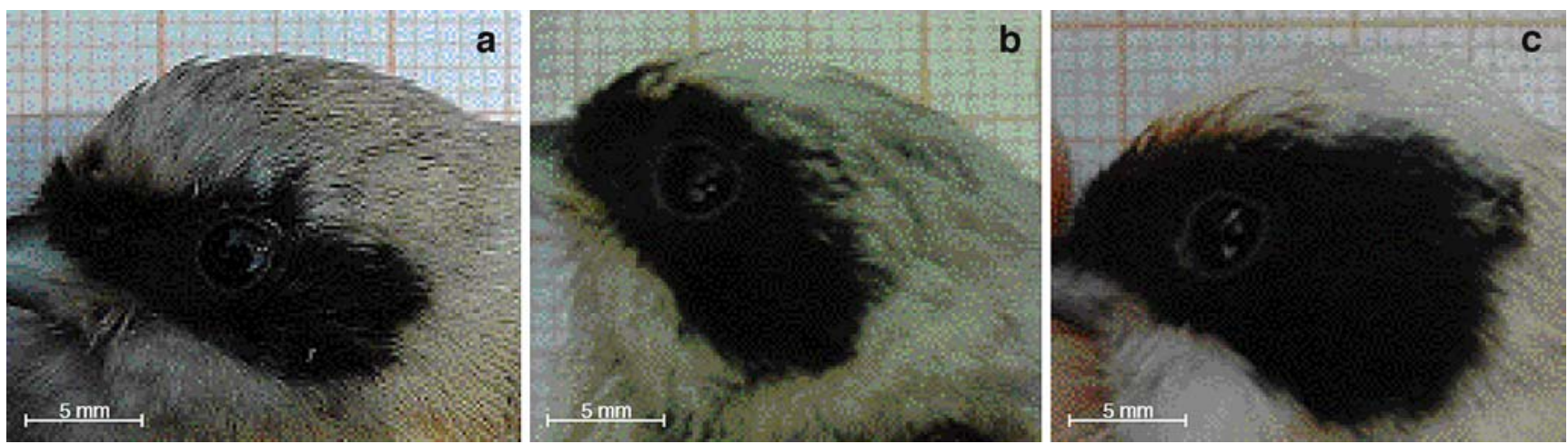

Fig. 1 Mask of a female $\left(\mathbf{a} 1.04 \mathrm{~cm}^{2}\right)$ and two male penduline tits. The male in the middle $(\mathbf{b})$ has a small mask $\left(1.10 \mathrm{~cm}^{2}\right)$ and the male on the right (c) a large mask $\left(1.80 \mathrm{~cm}^{2}\right)$ 
blood samples. Hematocrit value (i.e., the proportion of erythrocytes in the blood) signals the amount of oxygen transport capacity (Hammond et al. 2000) and thus work load (Ots et al. 1998; Piersma et al. 2000; Bleeker et al. 2005), and there are indications that birds with higher hematocrit are in better condition (Svensson and Merilä 1996; Piersma et al. 2000). Hematocrit value was assessed by taking a $50-$ to $100-\mu l$ blood sample from the bird's brachial vein into a heparinized blood capillary tube. Within $1 \mathrm{~h}$, the samples were centrifuged for $10 \mathrm{~min}$ at 9,000 rotations per minute. The heights of red blood cells and blood plasma in the capillary tube were measured three times using a sliding calliper $( \pm 0.1 \mathrm{~mm})$. The mean length of each column was used in the analyses. The hematocrit value was calculated as packed red blood cell volume divided by total blood volume. Previous studies found that hematocrit values are highly repeatable (90-99\%; Ots et al. 1998; Potti et al. 1999).

The absence/presence of a visible buffy coat layer in the capillary tube was also noted. Buffy coat represents the presence of white blood cells (Dein 1986) so that the presence of these cells indicates acute (or chronic) infections or disease (Harrison and Harrison 1986, Ots et al. 1998, Gustafsson et al. 1994). The height of the buffy coat layer in the capillary tube was small (mean $\pm \mathrm{SE}, 0.16 \pm 0.021 \mathrm{~mm}$ ) and was thus hard and unreliable to measure. Therefore, we decided to use a binary variable (absence/presence) in the analyses.

\section{Measuring aggression}

Aggressive behavior of males was assessed in two ways. First, a new male took over the nest from the resident male at seven nests (in four out of seven cases, the male took over both the nest and his mate), and the mask sizes of both males were known. In a paired comparison, we investigated whether usurping males had larger mask than evicted males. Second, we tested males' aggressivity before trapping them in an experiment based on classic studies of territorial aggression (e.g., Hansen and Rohwer 1986). In 2003, we challenged resident unmated males during nest building of their first nest using a dummy male penduline tit and song playback, placed about $15 \mathrm{~m}$ from his nest. The dummy has been made of wood and painted accurately to resemble a male penduline tit. Previous experience showed that penduline tits treat the dummy as an intruding male (Szentirmai I., personal observation). Masks do not reflect in ultraviolet (S.A. Kingma, J. Komdeur, P. Korsten, unpublished data); therefore, we are confident that potential color differences between the dummy and real birds in reflectance between 300 and $400 \mathrm{~nm}$ unlikely to influence our results. For song playback, we used an unfamiliar song that had been recorded in a different penduline tit population. Throughout the experiment, the same dummy and the same song recording were used to make responses comparable across resident males. The experimental setup resembled natural situations when roaming males challenge the resident. We then recorded (1) latency (in seconds) as the time between the start of the playback and the arrival of the resident male within $10 \mathrm{~m}$ from the dummy; and (2) once the resident male had arrived, we estimated the distance (in centimeters) between the resident male and the dummy every $20 \mathrm{~s}$ for $5 \mathrm{~min}$ and calculated the mean of these distances; (3) the number of physical attacks by the resident male in the $5 \mathrm{~min}$; and (4) the number of times that the resident male was counter-singing the playback during the entire $5 \mathrm{~min}$. All males were caught and color-banded immediately after the experiment. Intruding neighboring males were never observed during the experiments, and we confirmed for all males that they were the residents by observations at the nest within 2 days.

\section{Mating success}

We used two measures of male mating success: (1) whether the male was successful in attracting a female and (2) mating latency. If the male abandoned his nest before mating, he was termed unsuccessful. As females lay one egg per day, the start of egg laying was back-calculated from the number of eggs in an incomplete clutch. Egg laying starts shortly after pairing, and we had more data on egg laying than on mating date; therefore, we defined mating latency as the number of days between nest initiation and start of egg laying. We followed males throughout the breeding season and determined their total number of mates attracted during the entire breeding season.

\section{Parental care}

We checked the nests of mated males at least every other day for $15 \mathrm{~min}$ to establish whether the male, the female, or both parents deserted the clutch. Desertion by a parent was recognized if the parent was not observed at the nest for at least two consecutive checks (Szentirmai et al. 2005). Predation is an unlikely explanation for the 'disappearance' of penduline tit parents because (1) in most cases, deserting individuals (58 out of 89 males and 66 out of 78 females) were resighted later in the same season or in subsequent years, (2) the 'disappearance' of parents is not scattered through incubation and brood rearing, but characteristically concentrated during a short (2-3 days) interval during egg laying (van Dijk et al. 2007), and (3) frequencies of 'disappearance' are highly consistent between different populations of penduline tits (see Persson and Öhrström 1989), whereas one may expect local variations if predation of adults cause the disappearance. 
If one parent stayed with the clutch, we observed its incubation and nestling provisioning behavior. All observations were carried out with binoculars at $10-20 \mathrm{~m}$ from the nest using a hide. Between the seventh and tenth day of incubation, three observations of $1 \mathrm{~h}$ each were conducted between 1600 and 1900 hours to measure the time the parent spent in the nest. Incubation rate was calculated as the mean proportion of time inside the nest during the three observation periods. Nestling provisioning was recorded during three observations between the 4th and 6th, 9th and 11th, and 14th and 16th days after the first chick hatched, between 0600 and 1000 hours. For each parent (either the male or the female), feeding rate was calculated by counting the number of times the parent fed the young during $30 \mathrm{~min}$, averaged for the three observations.

\section{Reproductive success}

We counted the number of eggs between the seventh and ninth day of incubation and the number of chicks at hatching (hatchlings, 14 days after the start of incubation, Cramp et al. 1993), at the age of 10 days (nestlings) and at fledging (fledglings; 21 days after hatching). Hatching success was calculated as the proportion of eggs that resulted in hatchlings, and nestling survival was calculated as the proportion of hatchlings that survived until the age of 10 days. Annual reproductive success of males was estimated as the total number of their nestlings produced in all of their nests over the entire breeding season. We used the number of nestlings instead of the number of fledglings as a measure of reproductive success because we had more data on the former; these two variables were highly correlated in those nests in which we knew both (Spearman rank correlation: $R_{\mathrm{S}}=0.8, N=33$ nests, $\left.P<0.001\right)$. We analysed clutches cared by male only or female only separately because reproductive success depends on the sex of the caring parent (Szentirmai et al. 2007). As only 6 out of 37 males had more than one clutch, we used mean reproductive success of their clutches. Extra-pair paternity is reported to be rare in penduline tits $(6.9 \%$ of all young; Schleicher et al. 1997); therefore, we believe our measure of reproductive success adequately reflects the actual reproductive success.

\section{Data processing and statistical analyses}

Body size may confound the relationships between mask size and behavior (Green 2001); nevertheless, in our study, mask size was unrelated to body size (as measured by tarsus length) both in males $(R=0.1, N=86, P=0.26)$ and females $(R=0.003, N=21, P=0.80)$. Hence, we use absolute mask sizes (in $\mathrm{cm}^{2}$ ) in all analyses.

We analyzed the relationships between mask size and (1) male mating success, and (2) the total number of his mates during the breeding season. Furthermore, for males that had attracted a female, we calculated the number of days between nest initiation and mate attraction (mating latency).

Mask sizes may co-vary with other presumed sexually selected traits, for instance, nest size (Hoi et al. 1994; Szentirmai et al. 2005, Pogány and Székely 2007). However, we did not correct for nest volume because mask size was not associated with nest volume [generalized linear mixed model (GLMM) using nest volume as response variable, male identity as random factor; mask size: $t=0.08$, $P=0.94$; year: $t=1.6, P=0.13$; date of nest initiation: $t=1.7$, $P=0.11]$. In addition, in an aviary study of penduline tits, Pogány and Székely (2007) found no effect of nest size on female choice in contrast to mask size.

To analyze the effects of mask size on parental care, we investigated parental decisions (care or desert) of males and females in relation to the males' mask size. Second, we related incubation and feeding rates to the mask size of males.

We included potentially confounding variables (see "Results") with two-way interactions in the initial models. Non-significant variables and interactions were then removed by backward elimination. For each predictor, we present the results of final models. When we used several nests of the same male, we included the males' identity (ID) as a random factor in the statistical models (Venables and Ripley 2002). We used GLMM with binomial error distribution for binary response variables (male mating success, desertion decision), linear mixed-effects models (LME) for normally distributed response variables (mating latency), analysis of covariance (ANCOVA, number of eggs, hatching success, nestling survival, and number of nestlings per nest) and general linear model with Poisson error distribution (total number of nestlings). Statistical analyses were performed by SPSS 13.0 for Windows, and LMEs, GLMs, and GLMMs were fitted by R 2.2.0b ( $\mathrm{R}$ Development Core Team 2005; Ihaka and Gentleman 1996). In GLMMs, we used penalized quasi-likelihood estimation method (glmmPQL function). For normally distributed variables, we report means \pm standard errors. Mating latency and total number of mates were ' $\log (x+1)$ ' transformed, and hatching success and nestling survival were arcsine transformed (Sokal and Rohlf 1995). To balance type I and II errors, we followed the recommendations of Nakagawa (2004) and estimated effect sizes and the associated $95 \%$ confidence intervals (CI) to evaluate the strength and direction of each relationship and the level of uncertainty associated with each estimate. We report the correlation effect size $(R)$ and its confidence intervals (lower CI, upper CI) for the covariates in linear models and Cohen's $d$ for $t$ tests (Cohen 1988). Probability values are two-tailed, and the null hypothesis was rejected at $P<0.05$. 


\section{Results}

Mask size and individual quality

Males had significantly larger masks than females (on average 38\% larger; Fig. 2a). Mask size was more variable than tarsus length in both males and females (males: coefficient of variation, $\mathrm{CV}$ of mask size $=13.6$; $\mathrm{CV}$ of (tarsus length $)^{2}=4.7$; females: $\mathrm{CV}$ of mask size $=17.7 ; \mathrm{CV}$ of (tarsus length $\left.)^{2}=4.6\right)$. The masks of males and females within a pair were not related $(R=0.1, N=23$ pairs, $P=$ $0.54)$; thus, penduline tits do not seem to mate assortatively with regards to mask size. Yearling males (banded as nestlings in the previous year) had smaller masks than older males (banded as adults; Fig. 2b). Three males were caught both in 2003 and 2004, and the change in their mask size was consistent with the latter result $\left(2003,1.36 \pm 0.13 \mathrm{~cm}^{2}\right.$; $\left.2004,1.54 \pm 0.13 \mathrm{~cm}^{2}\right)$. Initiation date of males' first nest was not related to their mask size $\left(R^{2}=0.02, \beta=-0.001 \pm\right.$ $0.001, P=0.23$ ).

Males' mask size increased with body condition [multiple linear regression, overall model: $R^{2}=0.06, F_{2,83}=3.8$, $P=0.026$; body mass: $R(\mathrm{CI})=0.3(0.06,0.45), P=0.014$; tarsus length: $R(\mathrm{CI})=-0.2(-0.40,0.01), P=0.062$. Males with a buffy coat on their separated blood had larger masks than males without buffy coat (Fig. 2c), and mask size was unrelated to hematocrit values $(R(\mathrm{CI})=0.07(-0.24,0.36)$, $N=42, P=0.67)$. Female mask size was unrelated to body condition (multiple linear regression, overall model: $R^{2}=$ $0.1, F_{2,18}=0.03, P=0.97$; body mass: $R(\mathrm{CI})=-0.02$ $(-0.45,0.41), P=0.92$; tarsus length: $R(\mathrm{CI})=-0.06$ $(-0.48,0.39), P=0.82)$, buffy coat presence on separated blood ( $t$ test: $\left.t_{10}=-0.4, P=0.71\right)$, and hematocrit values $(R$ $(\mathrm{CI})=-0.3(-0.76,0.37), P=0.38)$.

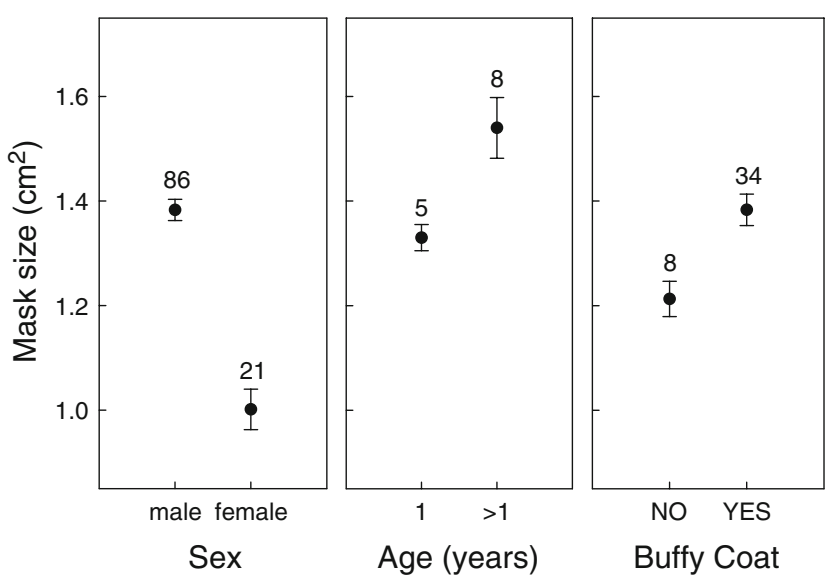

Fig. 2 Mask size of a males and females ( $t$ test: $\left.t_{106}=8.4, P<0.001\right)$, b 1 -year-old males and males older than 1 year $\left(t\right.$ test: $t_{12}=2.6, P=$ 0.023 ), and $\mathbf{c}$ males without and with buffy coat in their blood sample ( $t$ test: $t_{40}=3.8, P=0.001$ ). Error bars represent mean $\pm \mathrm{SE}$, and numbers denote sample sizes
Male-male interactions

Mask sizes were not different between usurping males $\left(1.52 \pm 0.07 \mathrm{~cm}^{2}\right)$ and evicted males $\left(1.41 \pm 0.06 \mathrm{~cm}^{2}\right.$; paired $t$ test: $\left.t_{6}=1.4, P=0.21\right)$. This result is, however, based on seven males, and although the effect size is medium to large (Cohen's $d=0.69)$, the CI appears to be wide $(-0.48,1.66)$, and therefore, the estimate could be regarded as uncertain. However, when using single correlations in the model presentation experiment, mask size was unrelated to levels of aggression (latency time, $R_{S}=0.1, N=30, P=0.52$; estimated distance to the dummy, $R_{S}=0.2, N=31, P=0.25$; physical attacks, $R_{s}=-0.2, N=31, P=0.31$; times singing, $\left.R_{s}=-0.007, N=31, P=0.97\right)$.

From the preceding four response variables, we extracted two principal components; the first one explained $37.75 \%$ and the second $28.06 \%$ of the variance (in total, $65.81 \%$, $N=30$ males). Consistent with the bivariate analyses, neither principal component related to mask size (PC1, $\left.R^{2}=0.04, P=0.30 ; \mathrm{PC} 2, R^{2}=0.001, P=0.90\right)$. The latter relationships remained non-significant when potential confounding variables were included in the models (date and time of the experiment and nest stage; results not reported).

\section{Mating success}

Mask size did not predict whether a male successfully attracted a female or not (Table 1). However, mating latency decreased significantly with increasing male mask size (Table 1 and Fig. 3a), and males with larger masks attracted more females over a breeding season than males with smaller masks (Table 2 and Fig. 3b).

\section{Parental care}

Mask size of males did not predict either their caring/ deserting behavior or the behavior of their mates' (Table 3). Neither incubation behavior nor feeding rate were related to male mask size (incubation, $F_{1,13}=0.9, P=0.38$; sex of caring parent, $F_{1,13}=0.3, P=0.57$; clutch size, $F_{1,13}=0.04$, $P=0.84$; feeding rate: male mask size, $F_{1,31}=0.07, P=0.79$; sex of caring parent, $F_{1,31}=2.6, P=0.12$; brood size, $F_{1,31}=$ $8.8, P=0.006)$.

Reproductive success

Number of eggs and hatching success were unrelated to male mask size (Table 4). However, both nestling survival and the number of nestlings decreased with male mask size (Table 4 and Fig. 3c). Finally, the annual reproductive success of males, including both nests cared by only the male and by only the female, was unrelated to their mask size (Table 2). 
Table 1 Mask size of male penduline tits (explanatory variable) in relation to whether a male mated and mating latency

\begin{tabular}{llllll}
\hline & Mating $(N=84$ males, 214 nests $)$ & & Mating latency $(N=77$ males, 161 nests $)$ \\
\cline { 2 - 3 } & $R(\mathrm{CI})$ & $P$ value & & $R(\mathrm{CI})$ & $P$ value \\
\hline Male mask size & $0.01(-0.20,0.22)$ & 0.94 & & $-0.27(-0.46,-0.04)$ & 0.022 \\
Nest initiation date & $0.19(-0.02,0.39)$ & 0.08 & & $-0.49(-0.64,-0.29)$ & $<0.001$ \\
Year & $-0.04(-0.25,018)$ & 0.74 & & $-0.30(-0.50,-0.09)$ & 0.006 \\
\hline
\end{tabular}

See "Materials and methods" for details of the models.

\section{Discussion}

Dominance or attractiveness?

Our study shows that mating success of male penduline tits in our population increases with the size of their black masks and that mask size is more likely to be involved in female mate choice than male-male competition for mates. By experimentally challenging territorial males, we showed that various measures of nest-building males' aggressiveness against (model) intruder males were not related to the size of their mask. Although the question of whether responses towards models are representative of responses to all birds, or are just idiosyncratic to models, has been subject to debate (see Hurlbert 1984; Kroodsma 1989a, b; Searcy 1989 for a detailed discussion on this subject), three lines of evidence suggest that a male's aggression to a model may reliably reflect its ability to protect its territory. First, it has been shown that stuffed birds replicate the real threat of an invading male (e.g., Veen et al. 2000). Indeed, in our experiment, males responded intensively to the dummy, sometimes even by physically attacking it. Second, a subsequent aviary experiment on male-male competition in penduline tits confirmed our finding that mask size is unrelated to measures of aggression (Pogány and Székely, under review). Third, males with larger eyestripes were not more likely to be usurpers than victims in natural nest-overtakes.

We found two lines of evidence suggesting that mask size is sexually selected. First, males possess larger masks than females, and mask size is much more variable among males than are non-ornamental morphological traits like tarsus length, a pattern typical for sexually selected ornamental traits (e.g., Cuervo and Møller 1999; Kraaijeveld et al. 2004; Komdeur et al. 2005). Although sexual dimorphic ornaments do not necessarily have to be under current directional or stabilizing selection per se (e.g., Westneat 2006), in penduline tit males, bearing larger masks seem likely to be more attractive to females. Although males with larger masks were not more successful in attracting a female than males with smaller masks at each nest per se (potentially because females may well base their initial choice to settle with a certain male on other

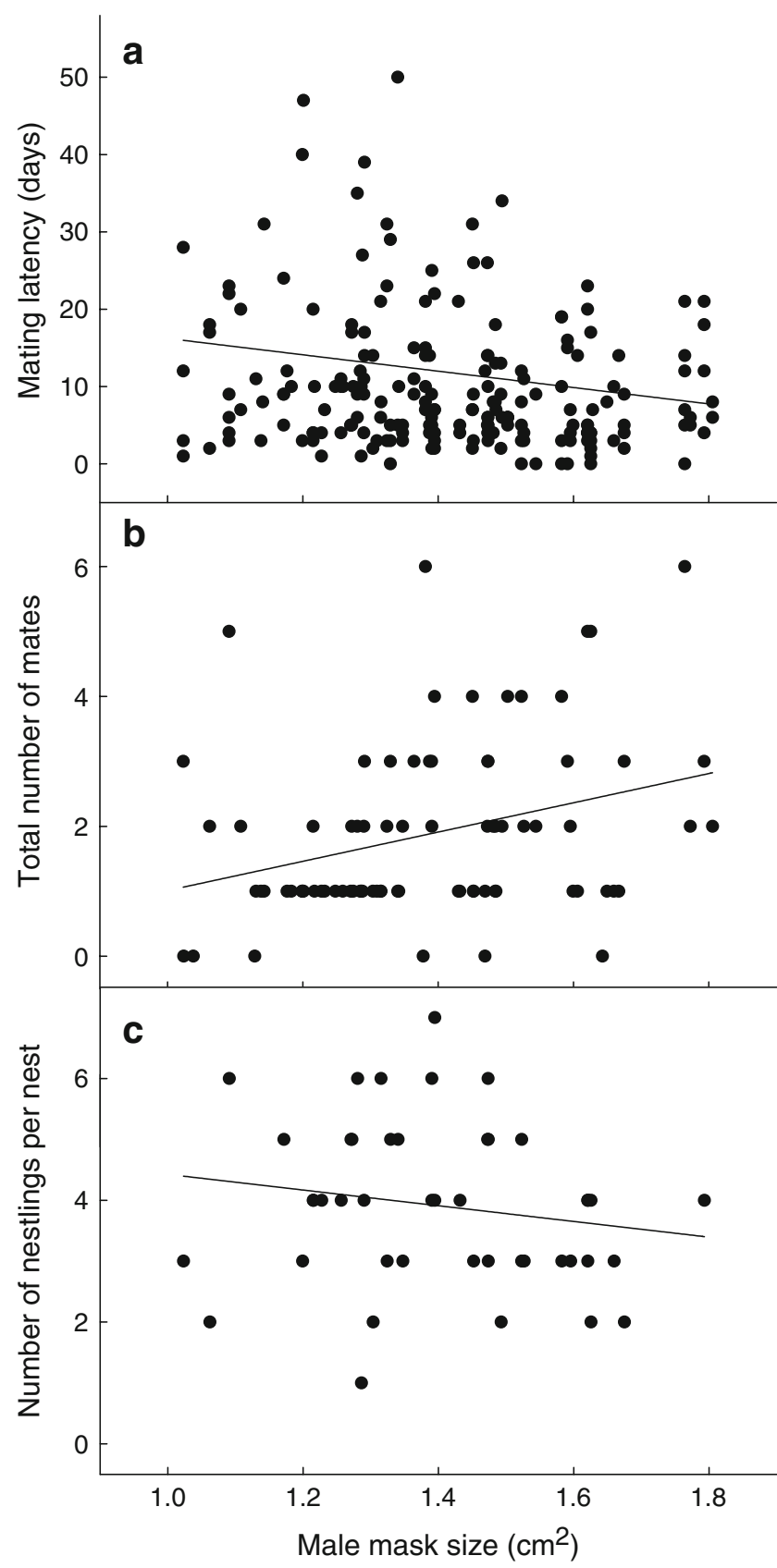

Fig. 3 Relationship between mask size and a mating latency (days) of male penduline tits, $\mathbf{b}$ the number of mates over the entire breeding season, and $\mathbf{c}$ the number of nestlings in female-care-only clutches. For illustrative purpose, each dot represents a datum, although note that in statistical analyses, we used LME (see "Materials and methods" and Tables 1 and 2) 
Table 2 Mask size of male penduline tits (explanatory variable) in relation to total number of females attracted and total number of nestlings produced over the entire breeding season

\begin{tabular}{lllll}
\hline & \multicolumn{2}{l}{ Number of mates $(N=81$ males $)$} & & Number of nestlings $(N=57)$ \\
\cline { 2 - 3 } & $R(\mathrm{CI})$ & $P$ value & & $R(\mathrm{CI})$ \\
\hline Male mask size & $0.23(0.01,0.42)$ & 0.045 & $-0.05(-0.30,0.22)$ \\
Length of breeding period & $0.70(0.57,0.80)$ & $<0.001$ & $0.28(0.02,0.50)$ & 0.73 \\
Year & $0.09(-0.30,0.13)$ & 0.42 & & $0.07(-0.19,0.33)$ \\
\hline
\end{tabular}

See "Materials and methods" for details of the models.

factors, like territory quality), they needed less time to acquire a mate and, consequently, they acquired more females during the breeding season. This result is consistent with an aviary experiment in the penduline tit, which showed that male dummies with larger masks are preferred by females (Pogány and Székely 2007), and adds to the growing evidence that melanin-based coloration may be a signal of attractiveness (Jawor and Breitwisch 2003; McGraw 2006). In addition, this finding is in line with an extensive study on common yellowthroats (Geothlypis frichas), in which males with larger similar facial masks have mating advantages over males with smaller masks (Thusius et al. 2001; Tarof et al. 2005; Pedersen et al. 2006). However, unlike penduline tits, facial masks in yellowthroats also appear to function in male-male competition (Tarof et al. 2005) probably evolved through the fact that reproductive success is determined by rather high levels of extra-pair paternity $(12.3-25.0 \%$ of young; Thusius et al. 2001), and thus in yellowthroats, competition among males is of larger importance (Thusius et al. 2001; Pedersen et al. 2006), compared to penduline tits (6.9\% of all young extra-pair; Schleicher et al. 1997).

Moreover, the positive correlation between mask size and body condition means that mask size could be a signal of quality (Jawor and Breitwisch 2003; McGraw 2003; Griffith et al. 2006). However, it has also been shown in other avian species that the degree of melanization may be heritable (Roulin et al. 1998; Roulin and Dijkstra 2003; Bize et al. 2006, Gasparini et al. unpublished results), and offspring of large-melanized males may be in better condition, as shown in cross-fostering experiments (Roulin et al. 2004; Bize et al. 2006, Roulin et al. unpublished results). This finding does not preclude that melanin ornaments may be a signal of quality per se, but covariation between melanization and body condition may occur even if coloration itself is not condition-dependent. Therefore, an experimental study on the condition dependence of mask size in penduline tits would greatly contribute to the understanding of ultimate factors underlying female preferences for melanin-based feather ornaments.

In spite of their higher mating success, males with larger masks did not obtain higher annual reproductive success than males with smaller masks. Although males that are more attractive had more mates over an entire breeding season, survival of their nestlings was lower, and consequently they did not fledge more nestling than less attractive males. This finding suggests that there is no positive selection on male mask size in our population; however, several factors may confound this result. For example, attractive males may increase the genetic diversity of their offspring by mating with many females. Alternatively, their offspring may have higher post-fledging survival prospectives (see below), and thus, their life-time reproductive success may be still higher than that of less attractive males (Richardson et al. 2004). In addition, it is known that short-term fitness consequences of the same male trait may differ among years and populations. For example, in house sparrows (Passer domesticus), different

Table 3 Parental decisions (care/desert) of male ( 89 clutches of 68 males) and female ( 78 clutches of 50 females) penduline tits in relation to male mask size (explanatory variable)

\begin{tabular}{|c|c|c|c|c|}
\hline & \multicolumn{2}{|l|}{ Male desertion } & \multicolumn{2}{|l|}{ Female desertion } \\
\hline & $R(\mathrm{CI})$ & $P$ value & $R(\mathrm{CI})$ & $P$ value \\
\hline Male mask size & $0.10(-0.14,0.33)$ & 0.42 & $-0.10(-0.37,0.19)$ & 0.52 \\
\hline Year & $-0.01(-0.25,0.23)$ & 0.93 & $0.004(-0.28,0.27)$ & 0.98 \\
\hline Desertion date & $-0.13(-0.36,0.11)$ & 0.30 & $-0.29(-0.53,-0.01)$ & 0.055 \\
\hline
\end{tabular}

Desertion date was included as a covariate, as parental decisions change over the breeding season (Persson and Öhrström 1989; Szentirmai et al. 2005). Because care by the male only occurred only after 24 June, we restricted the analysis to male decisions after this date. See "Materials and methods" for further details of the models. 
Table 4 Number of eggs, hatching success, nestling survival and number of 10 -day old nestlings in clutches tended by only the male ( $N=10$ nests of 10 different males) and the female ( $N=37$ males for the number of eggs and 36 for the other variables) in relation to male mask size

\begin{tabular}{|c|c|c|c|c|}
\hline & \multicolumn{4}{|l|}{ Clutch tended by } \\
\hline & \multicolumn{2}{|l|}{ Male alone } & \multicolumn{2}{|l|}{ Female alone } \\
\hline & $R(\mathrm{CI})$ & $P$ value & $R(\mathrm{CI})$ & $P$ value \\
\hline \multicolumn{5}{|c|}{ Number of eggs (response variable) } \\
\hline Male mask size & $0.27(-0.44,0.77)$ & 0.52 & $-0.08(-0.40,0.25)$ & 0.63 \\
\hline Year & $0.39(-0.32,0.82)$ & 0.34 & $0.19(-0.15,0.48)$ & 0.28 \\
\hline Desertion date & $-0.39(-0.82,0.32)$ & 0.34 & $-0.59(-0.77,-0.33)$ & $<0.001$ \\
\hline \multicolumn{5}{|c|}{ Hatching success (response variable) } \\
\hline Male mask size & $0.32(-0.39,0.79)$ & 0.44 & $-0.07(-0.39,0.26)$ & 0.68 \\
\hline Year & $-0.05(-0.66,0.60)$ & 0.91 & $0.11(-0.23,0.42)$ & 0.53 \\
\hline Desertion date & $0.16(-0.52,0.72)$ & 0.71 & $-0.16(-0.46,0.18)$ & 0.37 \\
\hline \multicolumn{5}{|c|}{ Nestling survival (response variable) } \\
\hline Male mask size & $0.04(-0.60,0.65)$ & 0.92 & $-0.34(-0.60,-0.01)$ & 0.05 \\
\hline Year & $-0.31(-0.79,0.40)$ & 0.46 & $-0.03(-0.36,0.30)$ & 0.85 \\
\hline Desertion date & $-0.35(-0.80,0.36$ & 0.39 & $0.01(-0.32,0.34)$ & 0.66 \\
\hline \multicolumn{5}{|c|}{ Number of nestlings (response variable) } \\
\hline Male mask size & $0.41(-0.30,0.83)$ & 0.32 & $-0.36(-0.62,-0.04$ & 0.037 \\
\hline Year & $-0.16(-0.72,0.53)$ & 0.71 & $0.33(0.004,0.60)$ & 0.055 \\
\hline Desertion date & $-0.51(-0.86,0.17)$ & 0.2 & $-0.50(-0.71,-0.21)$ & 0.002 \\
\hline
\end{tabular}

studies relating reproductive output to male melanin-based bib size found contrasting results, ranging from males with smaller bib fledging more young (Griffith et al. 1999), through no effect of bib size (Vaclav et al. 2002), to males with larger bibs fledging more young (Voltura et al. 2002; Jensen et al. 2004).

\section{Costs and benefits of attractive mates}

Our results indicate that mating to an attractive male may incur not only benefits but also costs for females. First, body mass of male penduline tits increased with mask size and older males had larger masks, in accordance with the suggestions that melanin ornaments may honestly reflect individual quality (Jawor and Breitwisch 2003; McGraw 2006). Thus, females of attractive males might have gained more viable offspring than females of less attractive males, as it has been shown in several other species (e.g., Norris 1993; Petrie 1994). However, in contrast to these studies, we found that offspring survival decreased with mask size in penduline tits. Therefore, high offspring viability, at least in the short-term, is unlikely to be an advantage of having an attractive mate. It is still possible that more attractive males sired more attractive offspring, and females of these males had higher lifetime reproductive success (e.g., Weatherhead and Robertson 1979; Gwinner and Schwabl 2005), although we had no data to test this possibility.

A second possibility is that females choose males with larger masks based on a better immune system of those males. However, the chance that a male had buffy coat in his blood increased with mask size, which may indicate acute or chronic infection of more attractive males (Dein 1986; Gustafsson et al. 1994). This result is consistent with studies in damselflies (Calopteryx splendens xanthostoma; Siva-Jothy 2000) and vertebrates (Abbas et al. 1991; Owens and Wilson 1999; Mackintosh 2001), which show that there may be a direct tradeoff between expression of melanization and immunity. Our result also supports the statement by Griffith et al. (2006) that it is well plausible that the expression of melanin ornaments is related to parasitic infections, as has also been shown in a study on great tits (Parus major; Fitze and Richner 2002). The poorer health status of attractive males (in terms of melanin sexual signals) might be explained by the immune-suppressive effects of developing exaggerated melanin ornaments (see Griffith et al. 2006). For example, the production of melanin may require high levels of immune-suppressive hormones (e.g., testosterone, Jawor and Breitwisch 2003; Bókony et al. 2008). Therefore, males with larger masks may be more prone to infections (Folstad and Carter 1992; Roberts et al. 2004). If health status of males is transmitted to the offspring, this may well contribute to and explain the lower offspring survival in the nests of attractive males. On the other hand, it has also been shown in barn owls (Tyto alba) that blacker individuals are more resistant to parasites and are more immunocompetent (Roulin et al. 2001a), a pattern that may well apply in our study, for instance if good quality males maintain a buffy coat layer even when they have not been exposed to a pathogen. Thus, if this pattern holds for penduline tits, and if health status is heritable, long-term 
survival of their offspring might explain female preference for males with larger masks.

Altogether, contradicting explanations lead us to state that long-term studies on survival, incorporating experimental linking of condition, expression of signals, and immunocompetence, are necessary to explain the actual cost and benefits of melanin-based mask size in penduline tits and melanin ornaments in general. Experimental triggering of individual immune systems is necessary to rule out different explanations for the causal effect of immune systems on male mask size in penduline tits and subsequently in its role in female choice.

\section{Concluding remarks}

In conclusion, our study provides evidence that melaninbased masks of male penduline tits are evolved through sexual selection, and coupled with an experiment (Pogány and Székely 2007), it suggests that this selection pressure was likely female preference for males with larger masks. Although attractive males do not seem to obtain higher short-term reproductive success than less attractive ones, they may gain in the long-term from genetically diverse offspring produced by multiple females or from production of healthier and stronger offspring. Females pay costs for mating to an attractive male, as nestlings of these males survive less well to fledging, potentially because they are more prone to infections, but on the other hand, the surviving offspring might be more successful later on. Studies on long-term benefits are necessary to show whether and how sexual selection acts on male mask size in penduline tits. The proximate factors of mask size remain largely not understood, and therefore, benefits that females may gain from attractive mates (and thus the evolutionary basis of female preference) deserve further (experimental) investigations.

Acknowledgments We are grateful to Kiskunsági Nemzeti Park and to Szegedfish Ltd. for allowing us to work in Fehértó and for providing accommodation and facilities during field work. We thank Otília Menyhárt, René van Dijk, Gábor Bakacsi, Dóra Magyar, Péter Horváth, Szabolcs Kajdocsi, and Kenneth Hayes for assistance in the field and Thomas Dijkstra, Oscar Vedder, and Daryl Durk Scarse for useful discussions and comments. Alexandre Roulin, Dave Westneat, Kevin McGraw, and two anonymous reviewers provided extremely valuable comments on earlier versions of the manuscript. This research was supported by grants from OTKA (T043390) to TS and from 'Groninger Universiteits Fonds' and 'Marco Polo Travel Fund' to SAK and MB. Our study was carried out under licenses of Kiskunsági Nemzeti Park, Hungary (390-2/2003, 1097-5/2004) and Szegedfish Ltd.

Open Access This article is distributed under the terms of the Creative Commons Attribution Noncommercial License which permits any noncommercial use, distribution, and reproduction in any medium, provided the original author(s) and source are credited.

\section{References}

Abbas AK, Lichtman AH, Pober JS (1991) Cellular and molecular immunology, 3rd edn. Saunders, Philadelphia

Badyaev AV, Hill GE (2000) Evolution of sexual dichromatism: contribution of carotenoid- versus melanin-based coloration. Biol J Linn Soc 69:153-172

Bize P, Gasparini J, Klopfenstein A, Altwegg R, Roulin A (2006) Melaninbased coloration is a nondirectionally selected sex-specific signal of offspring development in the Alpine swift. Evolution 60:2370-2380

Bleeker M, Kingma SA, Szentirmai I, Székely T, Komdeur J (2005) Body condition and clutch desertion in the penduline tit Remiz pendulinus. Behaviour 142:1465-1478

Bókony V, Liker A (2005) Melanin-based black plumage coloration is related to reproductive investment in cardueline finches. Condor 107:775-787

Bókony V, Liker A, Székely T, Kis J (2003) Melanin-based plumage coloration and flight displays in plovers and allies. Proc R Soc Lond B 270:2491-2497

Bókony V, Garamszegi LZ, Hirschenhauser K, Liker A (2008) Testosterone and melanin-based black plumage coloration: a comparative study. Behav Ecol Sociobiol DOI 10.1007/s00265008-0551-2

Cohen J (1988) Statistical power analysis for the behavioural sciences. Erlbaum, Hillsdale

Cramp S, Perrins CM, Brooks DJ (eds) (1993) Handbook of the birds of Europe the Middle East and North Africa-birds of the Western Palearctic, vol 7. Oxford University Press, Oxford

Cuervo JJ, Møller AP (1999) Phenotypic variation and fluctuating asymmetry in sexually dimorphic feather ornaments in relation to sex and mating system. Biol J Linn Soc 68:505-529

Dale J (2006) Intraspecific variation in bird colors. In: Hill GE, McGraw KJ (eds) Bird coloration, vol 2. Function and evolution. Harvard University Press, Cambridge, MA, pp 36-86

Dein J (1986) Hematology. In: Harrison GJ, Harrison WR (eds) Clinical avian medicine. Saunders, London, pp 174-191

Fitze PS, Richner H (2002) Differential effects of a parasite on ornamental structures based on melanins and carotenoids. Behav Ecol 13:401-407

Folstad I, Carter AJ (1992) Parasites bright males and the immunocompetence handicap. Am Nat 139:603-622

Franz D (1991) Paarungssystem und Fortpflanzungsstrategie der Beutelmeise (Remiz pendulinus). J Ornithol 132:241-266

Franz D, Theiss N (1983) Brutbiologie und Bestandsentwicklung einer farbberingten Population der Beutelmeise Remiz pendulinus. Verh Ornithol Ges Bayern 23:393-442

Gonzalez G, Sorci G, Møller AP, Ninni P, Haussy C, De Lope F (1999) Immunocompetence and condition-dependent sexual advertisement in male house sparrows (Passer domesticus). J Anim Ecol 68:1225-1234

Gray DA (1996) Carotenoids and sexual dichromatism in North American passerine birds. Am Nat 148:453-480

Green AJ (2001) Mass/length residuals: Measures of body condition or generators of spurious results? Ecology 82:1473-1483

Griffith SC, Owens IPF, Burke T (1999) Female choice and annual reproductive success favour less-ornamented male house sparrows. Proc R Soc Lond B 266:765-770

Griffith SC, Parker TH, Olson VA (2006) Melanin- versus carotenoidbased sexual signals: is the difference really so black and red? Anim Behav 71:749-763

Gustafsson L, Nordling D, Andersson MS, Sheldon BC, Qvarnström A (1994) Infectious diseases reproductive effort and the costs of reproduction in birds. Philos Trans R Soc Lond B 246:323-331

Gwinner H, Schwabl H (2005) Evidence for sexy sons in European starlings (Sturnus vulgaris). Behav Ecol Sociobiol 58:375-382 
Hammond KA, Chappell MA, Cardullo RA, Lin R-S, Johnsen TS (2000) The mechanistic basis of aerobic performance variation in the red junglefowl. J Exp Biol 203:2053-2064

Hansen AJ, Rohwer S (1986) Coverable badges and resource defence in birds. Anim Behav 34:69-76

Harrison GJ, Harrison LR (1986) Clinical avian medicine and surgery. Saunders, Philadelphia

Hill GE (2006) Female mate choice for ornamental coloration. In: Hill GE, McGraw KJ (eds) Bird coloration, vol 2. Function and evolution. Harvard University Press, Cambridge, MA, pp 137-200

Hill GE, Brawner WR (1998) Melanin-based plumage coloration in the house finch is unaffected by coccidial infection. Proc $\mathrm{R}$ Soc Lond B 265:1105-1109

Hoi H, Schleicher B, Valera F (1994) Female mate choice and nest desertion in penduline tits Remiz pendulinus. Anim Behav 48: 743-746

Hurlbert SH (1984) Pseudoreplication and the design of ecological field experiments. Ecol Monogr 54:187-211

Ihaka R, Gentleman R (1996) R: A language for data analysis and graphics. J Comput Graph Stats 5:299-314

Jawor JM, Breitwisch R (2003) Melanin ornaments honesty and sexual selection. Auk 120:249-265

Jensen H, Saetre BE, Ringsby TH, Tufto J, Griffith SC, Ellegren H (2004) Lifetime reproductive success in relation to morphology in the house sparrow Passer domesticus. J Anim Ecol 73:599-611

Komdeur J, Oorebeek M, van Overveld T, Cuthill I (2005) Mutual ornamentation age and reproductive performance in the European starling. Behav Ecol 16:805-817

Kraaijeveld K, Gregurke J, Hall C, Komdeur J, Mulder RA (2004) Mutual ornamentation sexual selection and social dominance in the black swan. Behav Ecol 15:380-389

Kroodsma DE (1989a) Suggested experimental designs for song playbacks. Anim Behav 37:600-609

Kroodsma DE (1989b) Inappropriate experimental designs impede progress in bioacoustic research: A reply. Anim Behav 38:717-719

Lank DB, Smith CM, Hanotte O, Burke T, Cooke F (1995) Genetic polymorphism for alternative mating-bahvior in lekking male ruff Philomachus pugnax. Nature 378:59-62

Lemon RE, Weary DM, Norris KJ (1992) Male morphology and behavior correlate with reproductive success in the American redstart (Setophaga ruticilla). Behav Ecol Sociobiol 29:399-403

Lessells CM, Boag PT (1987) Unrepeatable repeatabilities: A common mistake. Auk 104:116-112

Mackintosh JA (2001) The antimicrobial properties of melanocytes, melanosomes, and melanin and the evolution of black skin. J Theor Biol 211:101-113

McGraw KJ (2003) Melanins, metals, and mate quality. Oikos 102: $402-406$

McGraw KJ (2006) Mechanics of melanin-based coloration. In: Hill GE, McGraw KJ (eds) Bird coloration, vol 1. Mechanisms and measurements. Harvard University Press, Cambridge, MA, pp 243-294

McGraw KJ, Hill GE (2000) Differential effects of endoparasitism on the expression of carotenoid- and melanin-based ornamental coloration. Proc R Soc Lond B 267:1525-1531

McGraw KJ, Mackillop EA, Dale J, Hauber ME (2002) Different colors reveal different information: how nutritional stress affects the expression of melanin- and structurally based ornamental plumage. J Exp Biol 205:3747-3755

Nakagawa S (2004) A farewell to Bonferroni: the problems of low statistical power and publication bias. Behav Ecol 15:1044-1045

Norris K (1993) Heritable variation in a plumage indicator of viability in male great tits Parus major. Nature 362:537-539

Ots I, Murumägi A, Hörak P (1998) Haematological health state indices of reproducing great tits: a response to brood size manipulation. Funct Ecol 12:750-756
Owens IPF, Wilson K (1999) Immunocompetence: a neglected life history trait or conspicuous red herring? Trends Ecol Evol 14:170-172

Parker TH, Stansberry BM, Becker CD, Gipson PS (2003) Do melanin- or carotenoid-pigmented plumage ornaments signal condition and predict pairing success in the Kentucky warbler? Condor 105:663-671

Pedersen MC, Dunn PO, Whittingham LA (2006) Extraterritorial forays are related to a male ornamental trait in the common yellowthroat. Anim Behav 72:479-486

Persson O, Öhrström P (1989) A new avian mating system: ambisexual polygamy in the penduline tit (Remiz pendulinus). Ornis Scand 20:105-111

Petrie M (1994) Improved growth and survival of offspring of peacocks with more elaborate trains. Nature 371:598-599

Piersma T, Koolhaas A, Dekinga A, Gwinner E (2000) Red blood cell and white blood cell counts in sandpiper (Philomachus pugnax): Effects of captivity season nutritional status and frequent bleedings. Can J Zool 78:1349-1355

Pogány A, Székely T (2007) Female choice in the penduline tit Remiz pendulinus: the effects of nest size and male mask size. Behaviour 144:411-427

Potti J, Moreno J, Merino S, Frias O, Rodriguez R (1999) Environmental and genetic variation in the haematocrit of fledgling pied flycatchers Ficedula hypoleuca. Oecologia 120:1-8

Quinn VS, Hews DK (2003) Positive relationship between abdominal coloration and dermal melanin density in phrynosomatid lizards. Copeia 2003:858-864

Richardson DS, Komdeur J, Burke T (2004) Inbreeding avoidance, heterozygosity, and survival in Seychelles warblers. Evolution 58:2037-2048

Roberts ML, Buchanan KL, Evans MR (2004) Testing the immunocompetence handicap hypothesis: a review of the evidence. Anim Behav 68:227-239

Roulin A (1999) Nonrandom pairing by male barn owls (Tyto alba) with respect to a female plumage trait. Behav Ecol 10:688-695

Roulin A (2004) The evolution, maintenance and adaptive function of genetic colour polymorphism in birds. Evolution 79:815-848

Roulin A, Dijkstra C (2003) Genetic and environmental components of variation in eumelanin and phaeomelanin sex-traits in the barn owl. Heredity 90:359-364

Roulin A, Richner H, Ducrest AL (1998) Genetic, environmental, and condition-dependent effects on female and male ornamentation in the barn owl Tyto alba. Evolution 52:1451-1460

Roulin A, Jungi TW, Pfister H, Dijkstra C (2000) Female barn owls (Tyto alba) advertise good genes. Proc R Soc Lond B 267:937-941

Roulin A, Riols C, Dijkstra C, Ducrest A-L (2001a) Female plumage spottiness signals parasite resistance in the barn owl (Tyto alba). Behav Ecol 12:103-110

Roulin A, Riols C, Dijkstra C, Ducrest A-L (2001b) Female- and male-specific signals of quality in the barn owl. J Evol Biol 14: $255-267$

Roulin A, Bize P, Ravussin PA, Broch L (2004) Genetic and environmental effects on the covariation between colour polymorphism and a life-history trait. Evol Ecol Res 6:1253-1260

Savalli UM (1995) The evolution of bird coloration and plumage elaboration. A review of hypotheses. Curr Ornithol 12:141-190

Schleicher B, Hoi H, Valera F, Hoi-Leitner M (1997) The importance of different paternity guards in the polygynandrous penduline tit Remiz pendulinus. Behaviour 134:941-959

Searcy WA (1989) Pseudoreplication, external validity, and the design of playback experiments. Anim Behav 38:715-717

Senar JC (1999) Plumage coloration as a signal of social status. In: Adams N, Slotow R (eds). Proc Int Ornithol Congress, vol. 22, pp 1669-1686 
Senar JC, Figuerola J, Domènech J (2003) Plumage coloration and nutritional condition in the great tit (Parus major): the roles of carotenoids and melanins differ. Naturwissenschaften 90:234-237

Siefferman L, Hill GE (2003) Structural and melanin coloration indicate parental effort and reproductive success in male eastern bluebirds (Sialia sialis). Behav Ecol 14:855-861

Siefferman L, Hill GE (2005) Evidence for sexual selection on structural plumage coloration in female eastern bluebirds (Sialia sialis). Evolution 59:1819-1828

Siva-Jothy MT (2000) A mechanistic link between parasite resistance and expression of a sexually selected trait in a damselfly. Proc R Soc Lond B 267:2523-2527

Sokal RR, Rohlf FJ (1995) Biometry: the principles and practice of statistics in biological research, 3rd edn. Freeman, New York

Studd MV, Robertson RJ (1985a) Evidence for reliable badges and status in territorial yellow warblers (Dendroica petechia). Anim Behav 33:1102-1113

Studd MV, Robertson RJ (1985b) Sexual selection and variation in reproductive strategy in male yellow warblers (Dendroica petechia). Behav Ecol Sociobiol 17:101-109

Svensson E, Merilä J (1996) Molt and migratory condition in blue tits: a seological study. Condor 98:825-831

Szentirmai I, Komdeur J, Székely T (2005) What makes a nest-building male successful? Male behavior and female care in penduline tits. Behav Ecol 16:994-1000

Szentirmai I, Székely T, Komdeur J (2007) Sexual conflict over care: antagonistic effects of clutch desertion on reproductive success of male and female penduline tits. J Evol Biol 20:1739-1744
Tarof SA, Dunn PO, Whittingham LA (2005) Dual functions of a melanin-based ornament in the common yellowthroat. Proc $\mathrm{R}$ Soc Lond B 272:1121-1127

Thusius KJ, Peterson KA, Dunn PO, Whittingham LA (2001) Male mask size is correlated with mating success in the common yellowthroat. Anim Behav 62:435-446

Václav R, Hoi H, Blomqvist D (2002) Badge size paternity assurance behaviours and paternity losses in male house sparrows. J Avian Biol 33:315-318

van Dijk RE, Szentirmai I, Komdeur J, Székely T (2007) Sexual conflict over parental care in penduline tits: the process of clutch desertion. Ibis 149:530-534

Veen T, Richardson DS, Blaakmeer K, Komdeur J (2000) Experimental evidence for innate predator recognition in the Seycelles warbler. Proc R Soc Lond B 267:2253-2258

Venables WN, Ripley BD (2002) Modern applied statistics with S, fourth edn. Springer-Verlag, Berlin Heidelberg New York

Voltura KM, Schwagmeyer PL, Mock DW (2002) Parental feeding rates in the house sparrow Passer domesticus: are larger-badged males better fathers? Ethology 108:1011-1022

Weatherhead PJ, Robertson RJ (1979) Offspring quality and the polygyny threshold: "the sexy son hypothesis". Am Nat 113: 201-208

Westneat DF (2006) No evidence of current sexual selection on sexually dimorphic traits in a bird with high variance in mating success. Am Nat 167:E171-E189

Zucker N (1994) A dual status-signalling system: a matter of redundancy or differing roles? Anim Behav 47:15-22 